\title{
Marital Interaction and Satisfaction: A Longitudinal View
}

\author{
John M. Gottman \\ University of Washington, Seattle
}

\author{
Lowell J. Krokoff \\ Department of Clinical and Family Studies \\ University of Wisconsin-Madison
}

\begin{abstract}
Two longitudinal studies of marital interaction were conducted using observational coding of couples attempting to resolve a high-conflict issue. We found that a different pattern of results predicts concurrent marital satisfaction than predicts change in marital satisfaction over 3 years. Results suggest that some marital interaction patterns, such as disagreement and anger exchanges, which have usually been considered harmful to a marriage, may not be harmful in the long run. These patterns were found to relate to unhappiness and negative interaction at home concurrently, but they were predictive of improvement in marital satisfaction longitudinally. However, three interaction patterns were identified as dysfunctional in terms of longitudinal deterioration: defensiveness (which includes whining), stubborness, and withdrawal from interaction. Hypotheses about gender differences in roles for the maintenance of marital satisfaction are presented.
\end{abstract}

Perhaps the oldest question in the research literature on marriage is, What distinguishes a happy marriage from one that is unhappy (Terman, Buttenweiser, Ferguson, Johnson, \& Wilson, $1938)$ ? To this we add the related longitudinal question, What distinguishes a marriage that will become more satisfying over time from one that will become less satisfying over time? At first glance, it might seem that the same set of features will provide the answer to both the contemporary and the longitudinal questions, but the possibility of different answers becomes quite strong on further consideration. For example, behaviors that are functional for "keeping the peace" in the present may leave unresolved critical areas of conflict that might undermine the relationship over time.

We examined these questions by using the microanalytic observation of behavior. Although research on marriage has been conducted since the $1930 \mathrm{~s}$, most of the early work relied exclusively on self-report and interview methods. The legacy of this early work was a number of good self-report measures of marital satisfaction with excellent psychometric properties of construct validity and discriminant validity as well as moderate levels of predictive validity (see Burgess, Locke, \& Thomes, 1971). Systematic observational research on marital interaction began in the 1970s (Weiss, Hops, \& Patterson, 1973), and in the following years, various observational coding systems have appeared in the literature (for a review see Filsinger, 1983). This work has contributed to the development of a model of marital distress that focuses on communication-skills deficits in conflict resolution. We used a convergence of two major systems, the Marital Interaction Coding System (MICS; Weiss \& Summers, 1983) and the Couples Interaction Scoring System (CISS; Gottman,

The authors would like to acknowledge the following research grants for support of this work: National Institute of Mental Health (NIMH) Grant MH29910 and NIMH Research Scientist Development Award K200257 to John M. Gottman.

Correspondence concerning this article should be addressed to John M. Gottman, Department of Psychology, Mail Stop NI-25, University of Washington, Seattle, Washington 98195.
1979). In addition to these coding systems, we present a new observational coding system for the first time, the Specific Affect Coding System (SPAFF).

The SPAFF was designed so that the global category of negative affect could be dismantled. For example, anger might not belong in the same category as sadness, and different specific affects might not necessarily function in the same way in a marital interaction (Gottman \& Levenson, 1986). The observational use of microanalytic codes may be useful in understanding the most consistent finding in the literature on marital interaction and marital satisfaction: the finding that negative interaction is much more common in the interaction of unhappily married couples than happily married couples, which has been reported in laboratories in the United States as well as in Europe (Gottman, 1979; Hahlweg, Revenstorf, \& Schindler, 1984; Levenson \& Gottman, 1983; Margolin \& Wampold, 1981; Raush, Barry, Hertel, \& Swain, 1974; Revenstorf, Hahlweg, Schindler, \& Vogel, 1985; Schaap, 1982; Ting-Toomey, 1982). In these studies, negative content codes as well as affects (e.g., anger, contempt, disgust) have been lumped into this negative category. However, when most authors have interpreted their results, they have usually invoked images of a couple in conflict responding to one another with anger (see, for example, Revenstorf et al., 1985; Margolin \& Wampold, 1981). However compelling these images seem, an analysis is needed that separates the global category of negative interaction into its components to determine whether anger is in fact the key to understanding marital distress.

With these points in mind, we used the first set of analyses in this report to code a single set of high-conflict marital interactions with two coding systems: the MICS and the CISS. We used the information from these systems to gain better understanding of (a) current marital satisfaction and (b) the generalizability of predictors of current levels of marital satisfaction to the prediction of change in marital satisfaction over time. We also included a generalizability check on the concurrent marital satisfaction measure by collecting a sample of marital interaction at home without an observer present. Gottman (1979) found 
that couples' interaction at home without an observer present was characterized by much more negative affect and by more negative affect reciprocity than their interaction in the laboratory.

The second set of analyses involved coding these interactions with the SPAFF system, which dismantles negative affect into anger, contempt, fear, sadness, and whining categories. These analyses included a second sample of 30 couples who also varied in marital satisfaction.

\section{Method}

\section{Subjects}

For our first analysis, we selected 25 couples who varied widely in marital satisfaction from a larger sample of 52 couples used in another study (Krokoff, Gottman, \& Roy, in press). The larger sample had been recruited from the Champaign-Urbana, Illinois, community using a multistage recruitment procedure consisting of random telephone interviews, direct mailings, and informational meetings. Detailed information about the recruitment of these subjects is available in Krokoff (1987). The larger study systematically studied blue-collar and whitecollar marriages. In the subsample we selected for this multiple coding study, we picked couples who were lowest and highest in marital satisfaction, balancing occupational variables between the two groups. Couples in the Champaign-Urbana sample had the following demographic characteristics: At Time 1, the mean age for husbands was 46.63 years $(S D=$ $15.81)$, and the mean age for wives was 44.20 years $(S D=16.59)$. Subjects had been married an average of 23.9 years; the average marital satisfaction score, averaging across both self-report measures, was 105.1 $(S D=30.7)$ for husbands and $103.1(S D=31.8)$ for wives.

To gain additional power for the SPAFF analyses, we added to our first sample one that had already been coded with the SPAFF. This second sample consisted of 30 additional couples from another study of marital interaction. These 30 couples also varied widely in marital satisfaction. They lived in Bloomington, Indiana, only a few hours' drive from Champaign-Urbana. Detailed information about subject recruitment is available in Levenson and Gottman (1983). Couples in the Bloomington sample at Time 1 had the following demographic characteristics: The mean age for husbands was 30.32 years $(S D=4.47)$, and the mean age for wives was 29.80 years $(S D=4.77)$. Couples had been married an average of 4.2 years; the mean marital satisfaction score was 112.5 $(S D=20.7)$ for husbands and $110.9(S D=24.4)$ for wives.

\section{Procedure}

Marital satisfaction. The major criteria that we examined were concurrent marital satisfaction and changes in marital satisfaction. In both studies, the Locke-Wallace (Locke \& Wallace, 1959) and the Locke-Williamson (Burgess et al., 1971) scales were administered to each spouse at the initial assessment (Time 1). Although these scales are old, they correlate very highly (usually in the high 80 s or low 90 s) with more recently developed scales that are in wider use, such as the Marital Adjustment Scale (Spanier, 1976). We selected these scales to be consistent with other research based on the CISS and the MICS in the last decade. Three years after the Time 1 assessment, couples who were located and who agreed to participate were mailed a packet that included the two marital satisfaction questionnaires and a general information questionnaire. Change scores and the deviation of change controlling for Time 1 scores (the regression equivalent of the partial correlation) were very highly correlated in both samples: in the Champaign sample, $r(23)=$ 0.97 , and in the Bloomington sample, $r(23)=0.68$; thus, only change scores were used as a criterion variable. The follow-up of the Champaign-Urbana sample was conducted after that of the Bloomington sam- ple. In the Bloomington sample, we were able to recontact $63 \%$ of the couples, which is a rate that compares favorably with other longitudinal studies. In the Champaign-Urbana sample, we were able to recontact $96 \%$ of the couples. Two couples in the Champaign-Urbana sample had divorced and were dropped from the analyses. These couples constituted an inadequate sample size $n$ to analyze for predictors of divorce.

Laboratory videotapes and home audiotapes. In both samples, couples were videotaped for $15 \mathrm{~min}$ while they discussed a continuing and highly rated area of disagreement in their marriage on the Problem Inventory (see Gottman, 1979). This length of time has been found to be adequate in our previous research, in which the time has been varied from several hours to $15 \mathrm{~min}$ (Gottman, 1979; Levenson \& Gottman, 1983). In the Champaign-Urbana sample, couples identified two problems. One was randomly assigned to be discussed and audiotaped at home and the second was discussed and videotaped in the laboratory. The home audiotapes were transcribed and coded for the speaker's affect using the CISS affect codes (positive, neutral, and negative) as described in Gottman (1979). A random segment of each tape (about 4 min) was coded independently to check reliability. The Cohen's kappa (which assesses interobserver agreement beyond chance levels) for all CISS affect codes was 0.67 . Only negative affect is used in the present report because negative affect was found in Gottman (1979) to be the best discriminator between satisfied and dissatisfied couples. The Cohen's kappa for the negative affect code was 0.66. The kappas in this study are comparable to those in other studies based on the coding of affect from audiotapes (Gottman, 1979; Schaap, 1982). The Cronbach alpha generalizability coefficient for this code was 0.99 , indicating that this code has reasonable levels of interobserver reliability.

Observational coding systems. Three coding systems were used, the MICS, the CISS, and the SPAFF. The videotapes of the Champaign-Urbana sample were coded with all three systems. The videotapes of the Bloomington sample were coded with only the SPAFF. The MICS coding was completed under the supervision of Robert Weiss at the University of Oregon (see Weiss \& Summers, 1983, for a discussion of the MICS codes and for a review of studies that have used the MICS). The MICS codes were subdivided into the following subscales: (a) Positive Problem Solving, which is the sum of the accept responsibility, compromise, paraphrase/reflection, and positive solution codes; (b) Positive Verbal, which is the sum of the agreement, approval, and humor codes; (c) Positive Nonverbal, which involves only positive nonverbal behavior and is the sum of the assent, attends, smile/laugh, and physical positive codes; and (d) a subscale this report will call Compliance, which is the sum of the agreement, assent, and approval codes. We also formed four negative subscales: (a) Defensive, which is the sum of the excuse, deny responsibility and negative solution codes as well as the $z$ score for the sequence, mind reading by the partner followed by disagreement (Gottman, 1979, suggested that the mind reading-to-disagreement sequence can be characterized as defensiveness following what is perceived as a misattribution; recent versions of the MICS have included the CISS mind reading code); (b) Conflict Engagement, which is the sum of two codes, disagreement and criticism (criticism is a MICS code described by the coding manual as "a hostile statement expressing unambiguous dislike or disapproval of a specific behavior of the other" and requiring an "irritated or hostile tone of voice"; this code may involve the expression of anger); (c) Stubbornness, which is the sum of the noncompliance, put down, command, and complaint codes (according to the MICS coding manual, complaint includes statements of "being frequently deprived, wronged, or inconvenienced either through the partner's action or nonaction or because of external circumstances"; this code may involve the expression of whining); and (b) Withdrawal From Interaction, which is the sum of the following negative listener behaviors: no response, not tracking, turn off, and incoherent talk. The Cohen's kappa for this coding (all codes summed over all couples) was 0.72.

The CISS is described in Gottman (1979); the kappa for all CISS 
codes, summed over all couples, was 0.79 . The SPAFF is a new coding system. Coding with both the CISS and the SPAFF was conducted in our laboratory, with separate coders determining content with the CISS, affect with the CISS, and affect with the SPAFF.

In contrast to the affect codes of the CISS, which use specific physical features to categorize an utterance as positive, negative, or neutral, the SPAFF categorizes speech units by considering a gestalt consisting of verbal content, voice tone, context, facial expression, gestures, and body movement. In the version of the SPAFF used on these data, only the speaker's affect was coded. Each speech unit (i.e., speaker turn) was classified as affectively neutral, as one of five negative affects (anger, disgust or contempt, sadness, fear, whining), or as one of five positive affects (affection, humor, interest, anticipation, excitement or joy). In the Champaign-Urbana sample, the overall kappa for the SPAFF coding was 0.74 ; in the Bloomington sample, it was 0.71 . All interaction variables were converted to proportions within couples by dividing each code's frequency by the total number of observations for that interaction.

\section{Sequential Analyses}

Observational data were collected and analyzed as data in which each interactional unit receives one and only one code and in which codes can follow themselves. Within each couple, Bakeman's ELAG4 program was used to compute the Allison and Liker (1982) $z$ score of sequential connection. The $z$ score measures the direction and gain in prediction of the consequent code's occurrence given knowledge that the antecedent code has occurred. Only a part of the sequential matrix of antecedent-by-consequent affects were examined, namely, the negative affects and neutral affect. One type of variable was created from the $z$ scores of this matrix, namely, the sum of the $z$ scores of sequences in which a particular spouse responded with a specific affect. For example, the husband anger variable was the sum of the $z$ scores for all negative affect chains that ended with the husband's anger as the consequent code. This is thus an index of the extent to which the husband will respond with anger, independent of the antecedent code (accomplished by summing $z$ scores) and controlling for the base rates of the consequent code of anger (accomplished by using the $z$ scores, per se).

\section{Results}

The criterion variables were concurrent marital satisfaction, change in marital satisfaction, and the amount of husband and wife negative affect in the home interaction.

\section{Criterion Variables}

Marital satisfaction. Table 1 presents the correlations of the MICS codes with the criteria. As can be seen from Table 1, concurrent marital satisfaction and change in marital satisfaction were well-predicted by the global codes. In fact, in predicting the criterion variables from the global codes, the multiple correlations for the four criterion variables were $0.74(p<.001), 0.68$ $(p<.05), 0.79(p<.01)$, and $0.72(p<.01)$, respectively, for husband's marital satisfaction at Time 1 , wife's marital satisfaction at Time 1, and husband's and wife's change in marital satisfaction. These data also replicate the well-known result that, in the resolution of marital conflict, there is a stronger relation between concurrent marital satisfaction and negative interaction than positive interaction (see Gottman, 1979, for a review). On closer examination, one notices that the correlations between the husband's negative interaction and marital satisfaction and the husband's change in marital satisfaction are oppo- site. The husband's negative interaction predicted concurrent distress, but it predicted improvement in marital satisfaction over time. The same direction of results held for the wife's negative interaction, although they failed to reach significance. Also not significant was the negative correlation between the wife's positive interaction and change in marital satisfaction, whereas the reverse was true for concurrent marital satisfaction.

To understand these results, the codes of the MICS were analyzed in subscales. For the positive interaction scales, the interesting results were that, for the wife, positive verbal behavior strongly predicted concurrent marital satisfaction, but it predicted deterioration in marital satisfaction over time. Compliance by the wife also predicted deterioration in marital satisfaction over time. However, for the negative codes, conflict engagement predicted, for both partners, concurrent marital dissatisfaction but also improvement in marital satisfaction over time. Included in the Conflict Engagement subscale is the MICS criticism code, which, according to the coding manual, includes the expression of anger (see SPAFF results). A similar pattern of results was found for the other negative interaction subscales (i.e., Defensive, Stubborn, and Withdrawal), although only the husband's withdrawal reached statistical significance in predicting the deterioration of his marital satisfaction over time. However, the pattern of correlations supports the hypothesis that defensiveness, stubbornness, and withdrawal from interaction are predictive of concurrent distress and of the deterioration of marital satisfaction over time. The wife's withdrawal was more predictive than the husband's of concurrent distress, whereas the husband's withdrawal was more predictive than the wife's of change in marital satisfaction over time.

Home interaction. Table 1 shows that, in general, the MICS codes primarily predicted the husband's home negative affect (coded with the voice codes of the CISS). The husband's negative interaction in the laboratory, defensiveness, conflict engagement, and stubbornness positively predicted his negative affect at home, whereas his positive interaction, positive verbal behavior, positive nonverbal behavior, and his compliance correlated negatively with his negative affect at home. In contrast, only the wife's defensiveness predicted his negative affect at home. The home interaction variables made another contribution: They demonstrated that these relationships were robust to method variations in the criterion variables.

Summary. The most striking aspect of Table 1 is that a different pattern of results predicted concurrent marital satisfaction than predicted change in marital satisfaction over time. The next most striking aspect of Table 1 concerns the spousegender differences in the pattern of relations to criterion variables. In particular, it was revealed that positive verbal behavior and compliance expressed by wives may be functional in the short run but problematic in the long run. The opposite was true for both partners' conflict engagement, which predicted concurrent dissatisfaction with the marriage but improvement over time. On the other hand, some codes appeared to be dysfunctional both concurrently and longitudinally, namely, defensiveness, stubbornness, and withdrawal from interaction. Thus, conflict engagement of a specific kind may be functional longitudinally, but conflict that is indicative of defensiveness, stubbornness, and withdrawal may be dysfunctional longitudinally.

Collinearity. It is important to assess the amount of collinear- 
Table 1

Correlation of MICS Subscales With Criteria

\begin{tabular}{|c|c|c|c|c|c|c|}
\hline \multirow[b]{2}{*}{ Subscale variable } & \multicolumn{2}{|c|}{ Time 1 satisfaction } & \multicolumn{2}{|c|}{ Change } & \multicolumn{2}{|c|}{ Home negative } \\
\hline & Husband & Wife & Husband & Wife & Husband & Wife \\
\hline \multicolumn{7}{|l|}{ Global code } \\
\hline Husband positive & $.39^{\star}$ & .32 & -.12 & .07 & $-.54 * *$ & -.10 \\
\hline Wife positive & .32 & $.40^{*}$ & -.27 & -.24 & -.01 & -.32 \\
\hline Husband negative & $-.56^{* *}$ & $-.47^{* *}$ & $.76^{* * *}$ & $.63^{* * * *}$ & $.59^{* *}$ & .31 \\
\hline Wife negative & $-.60^{* *}$ & $-.57 * *$ & .25 & .32 & .02 & .11 \\
\hline \multicolumn{7}{|l|}{ Specific code } \\
\hline Husband positive problem & .28 & .31 & .11 & .14 & -.28 & $-.35^{*}$ \\
\hline Wife positive problem & .11 & .06 & .03 & .03 & -.04 & -.13 \\
\hline Husband positive verbal & .33 & .27 & -.23 & -.25 & $-.50^{* *}$ & -.01 \\
\hline Wife positive verbal & $.51^{* *}$ & $.58^{* *}$ & $-.41^{*}$ & $-.41^{*}$ & -.25 & -.23 \\
\hline Husband positive nonverbal & $.27^{*}$ & .18 & -.11 & .12 & $-.39^{*}$ & .00 \\
\hline Wife positive nonverbal & .17 & .27 & -.21 & -.19 & .07 & -.26 \\
\hline Husband defensive & $-.34^{*}$ & $-.35^{*}$ & -.31 & -.29 & $.53^{* *}$ & .06 \\
\hline Wife defensive & -.23 & -.17 & -.22 & -.20 & $.50^{* *}$ & .00 \\
\hline \multicolumn{7}{|l|}{ Husband conflict } \\
\hline engagement & $-.67^{* * *}$ & $-.64^{* * *}$ & $.50^{* *}$ & $.44^{*}$ & $.62^{* * *}$ & .13 \\
\hline Wife conflict engagement & $-.49^{* *}$ & $-.51^{* *}$ & .19 & $.43^{*}$ & .06 & .07 \\
\hline Husband compliant & .12 & .03 & -.08 & .06 & $-.48^{*}$ & .00 \\
\hline Wife compliant & .18 & .30 & $-.38^{*}$ & $-.46^{* *}$ & .10 & -.30 \\
\hline Husband stubborn & -.27 & -.23 & -.26 & -.28 & $.51^{* *}$ & .02 \\
\hline Wife stubborn & $-.41^{*}$ & $-.46^{*}$ & .07 & .09 & .04 & .22 \\
\hline Husband withdrawn & -.07 & -.08 & $-.36^{*}$ & -.23 & $.35^{*}$ & .25 \\
\hline Wife withdrawn & $-.66^{* * *}$ & $-.49^{* * *}$ & .27 & .04 & $.36^{*}$ & -.13 \\
\hline
\end{tabular}

Note . MICS = Marital Interaction Coding System. $d f \mathrm{~s}=23$ for Time 1 and 21 for change from Time 1 to Time 2.

${ }^{*} p<.05 . \quad{ }^{* *} p<.01 . \quad * * * p<.001$.

ity in these predictions. To assess this, multiple regressions were performed with the criterion variables as the dependent variables and the specific subscales of the MICS as the independent variables. To be cautious, these regressions were cut off after seven steps. The multiple correlations were (a) $0.90(p<.001)$ for husband's concurrent marital satisfaction, (b) 0.90 ( $p<$ .001 ) for wife's concurrent marital satisfaction, (c) 0.87 ( $p<$ .001 ) for change in the husband's marital satisfaction over time, (d) $0.88(p<.001)$ for change in the wife's marital satisfaction over time, (e) $0.94(p<.001)$ for the husband's negative affect at home, and (f) $0.73(p<.05)$ for the wife's negative affect at home. Hence, these relations were not characterized by collinearity, and the size of the multivariate predictions was strong.

\section{Further Specification of the Marital Interaction Variables}

Because the MICS does not separate content or separate what is being said from affect or from how it is being said, it is not possible to determine which of the aspects of the MICS interaction codes are doing the work in predicting the criterion variables. Therefore, we used the CISS system to partial out affect and to examine variation in content codes delivered with neutral affect, and we used the SPAFF system affect code itself in greater detail, independent of content.

CISS results. To deal with space considerations in this report, we used the CISS to test only two hypotheses: First, we tested whether the results obtained with the MICS Conflict Engagement subscale would be obtained with the CISS by examin- ing the wife's disagreement with neutral affect. We decided to focus on disagreement because it is most similar to the MICS Conflict Engagement subscale. If the same pattern of predictions had been obtained for concurrent versus change in marital satisfaction independent of negative affect, this would have demonstrated that raising disagreements, per se, is constructive in a longitudinal sense. Second, the CISS also permits further elaboration of the husband's mind reading by examining only mind reading with neutral affect, which Gottman (1979) reported as a functional behavior ("feeling probe") because it may function as a probe for the clarification of the other's feelings. Mind reading with neutral affect should not show the same pattern as other MICS defensiveness codes (negative correlations with concurrent marital satisfaction and negative correlations with change in marital satisfaction). Instead, neutral mind reading should correlate positively with the criteria. To assess these possibilities, we correlated the husband's and wife's disagreement with neutral affect only and the husband's and wife's mind reading with neutral affect only. Table 2 shows that disagreement with neutral affect correlated negatively with concurrent marital satisfaction but positively with change in marital satisfaction over time. Hence, the MICS results about conflict engagement hold, independent of negative affect. Thus, the confrontation of disagreement by itself is functional for marriage in a longitudinal sense.

Specific affect results. Table 3 is a summary of the SPAFF sequential analysis results, combining samples from Champaign-Urbana and Bloomington. Table 3 shows that it is the 
Table 2

Test of Content Independent of Affect Using CISS

Disagreement and Mind Reading Code

Correlations With Neutral Affect

\begin{tabular}{lcclccc}
\hline & \multicolumn{2}{c}{ Time 1 satisfaction } & & \multicolumn{2}{c}{ Change } \\
\cline { 2 - 3 } \cline { 6 - 7 } \multicolumn{1}{c}{ Variable } & Husband & Wife & & Husband & Wife \\
\hline Husband disagree & $-.38^{*}$ & $-.50^{* *}$ & & $.40^{*}$ & .32 \\
Wife disagree & -.27 & -.33 & & $.39^{*}$ & $.46^{*}$ \\
Husband mind read & -.27 & -.16 & & $.46^{*}$ & $.65^{* *}$ \\
Wife mind read & .06 & -.02 & & -.07 & -.05 \\
\hline
\end{tabular}

Note . CISS = Couples Interaction Scoring System. $d f s=23$ for Time 1 and 21 for change from Time 1 to Time 2.

$*<<.05$. ** $p<.01$

wife's expression of contempt and anger that correlated negatively with concurrent marital satisfaction and positively with change in her (and only her) marital satisfaction. The wife's fear predicted deterioration in her marital satisfaction, whereas her sadness predicted deterioration in both partners' marital satisfaction. The husband's whining predicted deterioration in his marital satisfaction. Whining is close to the MICS subscale that we have called Defensiveness.

It is thus likely that both the content and the affect components of the MICS codes in Table 1 are doing the work of predicting the criterion variables.

\section{Discussion}

Our major finding is that conflict engagement of a specific kind may be functional for a marriage longitudinally, but conflict that is indicative of defensiveness, stubbornness, and withdrawal (particularly on the part of husbands) may be dysfunctional longitudinally. It is clear from the present report that we cannot assume that, because interaction patterns correlate with concurrent relationship satisfaction, we can confidently label them "functional" or "dysfunctional." This fact has implica. tions for the design of therapeutic interventions with unhappily married couples. It is possible that couples who engage in conflict may pay a price in concurrent dissatisfaction and negative affect at home, but the strife may pay off in the long run, provided that the conflict does not invoke stubbornness, defensiveness, or withdrawal from interaction. An extreme of this pattern is the couple who avoid conflict entirely. Krokoff et al. (1988) found that many couples in their sample did not have a companionate set of expectations about marriage and that these couples characteristically avoided conflict in daily life. In the light of the present report, it might make sense to speculate that these conflict-avoiding couples are at some risk longitudinally. Perhaps, as Notarius and Vanzetti (1983) suggested, these couples never develop a sense of "relational efficacy," that is, the confidence that they can weather conflict together.

Second, interesting spouse differences were revealed in our results. Wives who are positive and compliant fare better in terms of their husbands' concurrent negative affect at home and concurrent marital satisfaction, but the marital satisfaction of these couples deteriorates over time. On the other hand, the stubbornness and withdrawal of husbands may be most harmful to the longitudinal course of marital satisfaction. In terms of specific emotions, the marital satisfaction of wives improves over time if wives express anger and contempt during conflict discussions but declines if the wives express sadness or fear. For husbands, only whining predicts change in marital satisfaction over time, and it predicts the deterioration of both partners' marital satisfaction. Thus, we cannot say that the same negative affects are equally positive or negative, in a longitudinal sense, for husbands and wives. In terms of recommendations for marriage, our results suggest that wives should confront disagreement and should not be overly compliant, fearful, and sad but should express anger and contempt. Husbands should also engage in conflict but should not be stubborn or withdrawn. Neither spouse should be defensive. How can we make sense of these spouse differences?

Several studies have suggested that wives are more likely than husbands to confront disagreements in their marriage (e.g., Burke, Weier, \& Harrison, 1976; Huston \& Ashmore, 1986; Krokoff, in press; Weiss, Hops, \& Patterson, 1973). In our data, we have generally noticed that in most conflict discussions either the wife begins by stating the issues or the husband begins and quickly defers to his wife for elaboration. However, there is another pattern that we have noticed in the marital research literature. Interview and questionnaire-based research has revealed that, in unhappy marriages, wives are described as conflict-engaging, whereas husbands are described as withdrawn. For example, there is a consistent spouse difference in marital complaints: Unhappily married women complain about their husbands being too withdrawn, whereas unhappily married men complain about their wives being too conflict engaging (Locke, 1951; Terman et al., 1938). Komarovsky (1962) reported that blue-collar husbands are self-disclosing in happy marriages but withdrawn in unhappy marriages. Rubin's (1979) interviews with married couples suggest that these unhappily married husbands may have withdrawn from intense negative affect. In research based on observational methods, these differences are mirrored. For example, when discussing

Table 3

Correlations of SPAFF Consequent Codes With Criterion Variables for Both Samples Combined

\begin{tabular}{llllll}
\hline & \multicolumn{2}{c}{ Time 1 satisfaction } & & \multicolumn{2}{c}{ Change } \\
\cline { 2 - 3 } \cline { 5 - 6 } \multicolumn{1}{c}{ Variable } & Husband & Wife & & Husband & Wife \\
\hline Husband contempt & $-.37^{* *}$ & $-.40^{* *}$ & & .14 & .20 \\
Wife contempt & $-.48^{* *}$ & $-.48^{* *}$ & & .16 & $.27^{*}$ \\
Husband anger & -.18 & -.22 & & -.16 & .01 \\
Wife anger & $-.35^{* *}$ & $-.42^{* *}$ & & .19 & .26 \\
Husband fear & .03 & .03 & & .10 & .12 \\
Wife fear & .02 & .08 & & -.24 & $-.29^{*}$ \\
Husband sadness & .05 & .07 & & -.22 & -.09 \\
Wife sadness & .15 & .20 & $-.35^{* *}$ & $-.26^{*}$ \\
Husband whining & -.10 & -.11 & $-.38^{* *}$ & -.19 \\
Wife whining & -.11 & -.12 & -.13 & -.03 \\
\hline
\end{tabular}

Note. SPAFF $=$ Specific Affect Coding System. $d f \mathrm{~s}=51$ for Time 1 and 39 for change from Time 1 to Time 2 .

$*<$ <.05. * $p<.01$ 
disagreements, wives act in ways designed to confront the issue and enforce their feelings about it, whereas husbands rely on more conciliatory and factual explanations (Margolin \& Wampold, 1981; Raush et al., 1974). When our results are added to this picture, they suggest the hypothesis that the wife, as the manager of marital disagreements, has to manage a complex dialectic.

We suggest this dialectic is as follows. If the wife must introduce and elaborate disagreements in marriages, our data suggest that, for the sake of long-term improvement in marital satisfaction, she may need to do this by getting her husband to confront areas of disagreement and to openly vent disagreement and anger. We propose that this will be functional for the longitudinal course of relationship satisfaction, but only if the interaction does not also result in his whining, his stubbornness, his withdrawal from interaction, or the defensiveness of both partners. These interaction patterns of whining, stubbornness, and withdrawal in a marriage, we suggest, are more deleterious if they are characteristic of husbands. We realize that this hypothesis is asymmetric with respect to gender, and we recognize that it is likely to be controversial. Nonetheless, it organizes a vast quantity of marital interaction data. The actual picture may be mediated by the intensity of the conflict. In fact, Gottman (1979) reported that men in satisfied marriages deescalate negative affect in low-conflict discussions, whereas women in satisfied marriages deescalate negative affect in high-conflict discussions; both spouses relinquish the deescalation role in unsatisfied marriages. Clearly, there is a great deal we need to learn about the longitudinal course of marital (and other) relationships across the life span.

\section{References}

Allison, P. D., \& Liker, J. K. (1982). Analyzing sequential categorical data on dyadic interaction: A comment on Gottman. Psychological Bulletin, 9I, 393-403.

Burgess, E. W., Locke, H. J., \& Thomes, M. M. (1971). The family. New York: Van Nostrand Reinhold.

Burke, R. J., Weier, T., \& Harrison, D. (1976). Disclosure of problems and tensions experienced by marital problems. Psychological Reports, 38, 531-542.

Filsinger, E. E. (Ed.). (1983). A sourcebook of marriage and family assessment. Beverly Hills, CA: Sage.

Gottman, J. M. (1979). Marital interaction: Experimental investigations. New York: Academic Press.

Gottman, J. M., \& Levenson, R. W. (1986). Assessing the role of emotion in marriage. Behavioral Assessment, 8, 31-48.

Hahlweg, K., Revenstorf, D., \& Schindler, L. (1984). Effects of behavioral marital therapy on couples' communication and problem-solving skills. Journal of Consulting and Clinical Psychology, 52, 553566.

Huston, T. L., \& Ashmore, R. D. (1986). Women and men in personal relationships. In R. D. Ashmore \& F. Del Boco (Eds.), The social psychology of female-male relations (pp. 167-210). New York: Academic Press.

Komarovsky, M. (1962). Blue-collar marriage. New York: Random House.

Krokoff, L. J. (1984). Anatomy of negative affect in working-class marriages. Dissertation Abstracts International, 45, 7A. (University Microfilms No. 84-22 109)
Krokoff, L. J. (in press). Interaction and cognitive styles correlated with negative affect: An exploratory study of gender differences in marital conflict resolution. Joumal of Family Issues.

Krokoff, L. J. (1987). Recruiting representative samples for marital research. Journal of Social and Personal Relationships, 4, 317-328.

Krokoff, L. J., Gottman, J. M., \& Roy, A. K. (1988). Blue-collar marital interaction and a companionate philosophy of marriage. Journal of Personal and Social Relationships, 5, 201-222.

Krokoff, L. J., Gottman, J. M., \& Roy, A. K. (in press). Expanding the range of marital interaction research: Marital happiness, occupational status, and communication orientation effects. Journal of Personal and Social Relationships.

Levenson, R. W., \& Gottman, J. M. (1983). Marital interaction: Physiological linkage and affective exchange. Joumal of Personality and Social Psychology, 45, 587-597.

Locke, H. J. (1951). Predicting adjustments in marriage: A comparison of a divorced and a happily married group. New York: Henry Holt.

Locke, H. J., \& Wallace, K. M. (1959). Short marital-adjustment and prediction tests: Their reliability and validity. Marriage and Family Living, 21, 251-255.

Margolin, G., \& Wampold, B. E. (1981). Sequential analysis of conflict and accord in distressed and nondistressed marital partners. Journal of Consulting and Clinical Psychology; 49, 554-567.

Notarius, C. I., \& Vanzetti, N. A. (1983). The marital agendas protocol. In Erik E. Filsinger (Ed.), Marriage and family assessment (pp. 209227). Beverly Hills, CA: Sage.

Raush, H. L., Barry, W. A., Hertel, R. K., \& Swain, M. A. (1974). Communication, conflict, and marriage. San Francisco, CA: Jossey-Bass.

Revenstorf, D., Hahlweg, K., Schindler, L., \& Vogel, B. (1985). Interaction analysis of marital conflict. In K. Hahlweg \& N. Jacobson (Eds.) Marital interaction: Analysis and modification (pp. 121-183). New York: Guilford Press.

Rubin, L. B. (1979). Worlds of pain. New York: Basic Books.

Schaap, C. (1982). Communication and adjustment in marriage. The Netherlands: Swets \& Feitlinger.

Spanier, G. B. (1976). Measuring dyadic adjustment: New scales for assessing the quality of marriage and similar dyads. Journal of Marriage and the Family, 38, 15-28.

Terman, L. M., Buttenweiser, P., Ferguson, L. W., Johnson, W. B., \& Wilson, D. P. (1938). Psychological factors in marital happiness. New York: McGraw Hill.

Ting-Toomey, S. (1982). An analysis of verbal communication patterns in high and low marital adjustment groups. Human Communication Research, 9, 291-302.

Weiss, R. L., Hops, H., \& Patterson, G. R. (1973). A framework for conceptualizing marital conflict: A technology for altering it, some data for evaluating it. In F. W. Clark \& L. A. Hamerlynck (Eds.), Critical issues in research and practice: Proceedings of the Fourth Banff International Conference on Behavior Modification (pp. 309342). Champaign, IL: Research Press.

Weiss, R. L., \& Summers, K. J. (1983). Marital Interaction Coding System-III. In E. Filsinger (Ed.), Marriage and family assessment (pp. 35-115). Beverly Hills, CA: Sage.

Wills, T. A., Weiss, R. L., \& Patterson, G. R. (1974). A behavioral analysis of the determinants of marital satisfaction. Journal of Consulting and Clinical Psychology, 42, 802-811.

Received March 7, 1988

Revision received March 25, 1988

Accepted March 25, 1988 